\title{
Ah receptor represses acute-phase response gene expression without binding to its cognate response element
}

\author{
Rushang D Patel ${ }^{1,2}$, lain A Murray ${ }^{1}$, Colin A Flaveny ${ }^{1,2}$, Ann Kusnadi ${ }^{1}$ and Gary H Perdew ${ }^{1}$
}

Repression of the nuclear factor- $\kappa \mathrm{B}(\mathrm{NF}-\kappa \mathrm{B})$ pathway has been extensively researched because of its pivotal role in inflammation. We investigated the potential of the aryl hydrocarbon receptor (AHR) to suppress NF- $\kappa$ B regulated-gene expression, especially acute-phase genes, such as serum amyloid A (Saa). Using AHR mutants, it was determined that nuclear translocation and heterodimerization with AHR-nuclear translocator are essential, but DNA binding is not involved in AHR-mediated Saa repression. A number of AHR ligands were capable of repressing Saa3 expression. AHR activation leads to a decrease in RELA and C/EBP/ $\beta$ recruitment to and histone acetylation at Saa3 gene promoter. A battery of acute-phase genes (eg C-reactive protein and haptoglobin) induced by cytokine exposure was repressed by AHR activation in mouse hepatocytes. Dietary exposure to an AHR ligand represses cytokine-induced acute-phase response in the liver. Use of a human liver-derived cell line revealed similar repression of Saa mRNA levels and secreted protein. Repression of AHR expression also enhanced Saa induction in response to cytokines, suggesting that AHR is capable of constitutively repressing Saa gene expression. These results establish a role for AHR in inflammatory signaling within the liver, presenting a new therapeutic opportunity, and signify AHR's ability to function in a DNAindependent manner.

Laboratory Investigation (2009) 89, 695-707; doi:10.1038/labinvest.2009.24; published online 30 March 2009

KEYWORDS: Ah receptor; serum amyloid; TCDD; Inflammation; acute-phase response; liver

The acute-phase response (APR) represents a major adaptive physiological first-line reaction to potentially deleterious environmental stresses including infection, inflammation, chemical stress and neoplastic growth. Homeostatic disruption by such factors initiates the APR, primarily within the liver, resulting in a complex, but highly coordinated, change in the pattern of hepatic gene expression. The stimulation and repression of a subset of predominantly secreted hepatic factors known as the positive and negative acute-phase proteins (APPs), respectively, signals to the body the need to respond to a perceived stress. Numerous proteins have been classified as belonging to the APP, including plasminogen, fibrinogen, C-reactive protein (CRP), $\alpha 1$-antitrypsin, $\alpha 2$ macroglobulin and serum amyloid A (SAA). ${ }^{1}$ Many APP are pleiotropic in nature and generally serve to modulate the immune system and metabolic processes to counteract a perceived stress. However, persistent pathophysiological conditions such as cancer or autoimmune diseases (eg rheumatoid arthritis) can lead to chronic stress and sustained APR induction with subsequent deleterious effects on immune signaling, catabolism, cachexia and amyloidosis. Consequently, clarification of the transcriptional regulation of specific APPs and the potential to modulate their expression has obvious clinical benefits.

Induction of the APR is principally driven through cytokine signaling and activation of transcription factors, such as nuclear factor- $\kappa \mathrm{B}(\mathrm{NF}-\kappa \mathrm{B})$, signal transducer and activator of transcription-3 (STAT3) and CCAAT enhancer-binding protein $\beta$ (C/EBP $\beta$ or NF-IL6). The transcriptional activity of $\mathrm{NF}-\kappa \mathrm{B}$ can be influenced by numerous factors, such as posttranslational modification of NF- $\kappa \mathrm{B}$ subunits or by cross-talk with other transcription factors (eg nuclear receptors). ${ }^{2}$ Recently, evidence has been provided implicating the aryl hydrocarbon receptor (AHR) or dioxin receptor as a modulator

\footnotetext{
'Department of Veterinary and Biomedical Sciences and Center for Molecular Toxicology and Carcinogenesis, The Pennsylvania State University, University Park, PA, USA and ${ }^{2}$ The Huck Institutes of the Life Sciences, The Pennsylvania State University, University Park, PA, USA

Correspondence: Dr GH Perdew, Department of Veterinary and Biomedical Sciences and Center for Molecular Toxicology and Carcinogenesis, The Pennsylvania State University, University Park, CMTC, 309 LSB, PA 16802, USA.

E-mail: ghp2@psu.edu
}

Received 12 November 2008; revised 7 January 2009; accepted 9 February 2009 
of NF- $\kappa$ B activity. ${ }^{3}$ AHR, a ligand-activated transcription factor belonging to the basic helix-loop-helix PAS protein family, has an established role in xenobiotic metabolism, driving the expression of detoxification enzymes, CYP1A1 being a prime example. AHR adheres to the paradigm of a ligand-activated transcription factor; ligand binding promotes the dissociation of AHR from a cytoplasmic chaperone complex, thus facilitating nuclear translocation of AHR. ${ }^{4}$ Nuclear AHR readily forms a heterodimer with AHR-nuclear translocator (ARNT), thus forming a competent transcription factor capable of binding cognate DNA dioxin response elements (DRE) and stimulating the expression of AHR target genes. ${ }^{5}$ Recent evidence suggests that AHR activity is not restricted solely to xenobiotic metabolism, but may also exert modulatory effects on diverse cellular processes through the phenomenon of receptor cross-talk. ${ }^{6}$

Here, evidence is presented highlighting the potential of AHR to negatively regulate the transcriptional activity of factors that regulate the inflammation response with particular emphasis on suppression of APP expression in the liver. Utilizing a murine in vivo model in conjunction with mouse and human cell culture systems, we show the capacity of ligand-activated AHR to directly attenuate cytokine-mediated induction of the APR component SAA mRNA and protein, as well as other APR genes. Furthermore, we show that this attenuation occurs in the absence of direct interaction of AHR and its cognate response element. This represents the first report documenting the ability of AHR to repress inflammatory signaling in a non-traditional manner, and highlights the potential of AHR as a target for the therapeutic management of inflammatory disease.

\section{MATERIALS AND METHODS Reagents and Mice}

Anti-RELA antibody (sc-372) and anti-C/EBP $\beta$ (sc-150) were purchased from Santa Cruz Biotechnology Inc. and antiacetyl-histone H4 (Lys5) antibody was purchased from Upstate. Affinity-purified anti-AHR rabbit polyclonal antibody was obtained from BioMol. Recombinant interleukins were purchased from PeproTech Inc. Hepalclc7 and Huh7 cells were obtained from the American Type Culture Collection and Curt Omiecinski (Penn State University, PA, USA), respectively. C57BL6/J mice were obtained from Jackson Laboratory, whereas $A h r^{f x / f x} C r e^{A l b}$ and $A h r^{-/-}$mice were gifts from Chris Bradfield (University of Wisconsin, Madison).

\section{AHR Ligand Dietary Exposure}

Female C57BL6/J and $\mathrm{Ahr}^{-1-}$ mice, 10- to12-week old, with mean weights $19.8 \pm 0.7 \mathrm{~g}$ and $16.9 \pm 1.4 \mathrm{~g}$, respectively, were used in this study. Mice were maintained on a standard 12-h light/dark cycle with ad libitum access to standard chow and water. Mice were given ad libitum access to purified AIN93 M (Dyets Inc.) or purified diet supplemented with $0.4 \mathrm{~g} / \mathrm{kg}$ $\beta$-NF for $18 \mathrm{~h}$ (overnight). The next day mice were given intraperitoneal (i.p.) injections of vehicle (phosphate- buffered saline) or $10 \mu \mathrm{g} / \mathrm{kg}$ murine interleukin-1 $\beta$ (IL1B)/ interleukin-6 (IL6), as indicated. At $4 \mathrm{~h}$ after i.p. injection, mice were killed by asphyxiation with $\mathrm{CO}_{2}$ and hepatic tissue was harvested.

\section{Cell Culture}

Hepalclc7 and Huh7 established cell lines were cultured in $\alpha$-minimum essential medium with $8 \%$ fetal bovine serum (FBS). SV-40 virus-immortalized $\mathrm{mAHR}^{-1-}$ hepatocytes were maintained in $\alpha \mathrm{MEM}, 10 \mathrm{nM}$ dexamethasone and $4 \%$ FBS at $34^{\circ} \mathrm{C}$. The cells were grown in the absence of dexamethasone during the experiments. Primary bone marrow (BM) cells were isolated from lower limb bones of 8 to 12week-old C57BL/6J mice; BM cells were cultured overnight in Dulbecco's Modified Eagle's Medium (DMEM) supplemented with $8 \%$ FBS and penicillin/streptomycin. Non-adherent cells were centrifuged and plated in DMEM supplemented with $10 \mathrm{ng} / \mathrm{ml}$ granulocyte-monocyte colonystimulating factor and $2 \mathrm{mM}$ glutamine. Half the volume of medium was replaced every day for 4 days before treatment.

\section{Primary Hepatocyte Isolation}

Primary murine hepatocytes were isolated by the in situ twostep perfusion method from mice. ${ }^{7}$ Hepatocytes were maintained in culture media (Hepatozyme-SFM (Invitrogen)/ $2.5 \% \mathrm{DMSO} / 10 \mathrm{nM}$ dexamethasone $/ 100 \mathrm{IU} / \mathrm{ml}$ penicillin and $100 \mu \mathrm{g} / \mathrm{ml}$ streptomycin). Cells were cultivated for 5 days before treatment.

\section{Expression Constructs}

Plasmid constructs pcDNA3-mAhR, pcDNA3-ARNT-HA, pEYFPmAhR, pCI-XAP2 and pGudLuc 6.1 were generated earlier. The mAhR mutant constructs, pcDNA3-mAhR $\Delta \mathrm{H} 1$ $(\Delta 43-51)$ and pEYFP-mAhR $\Delta \mathrm{H} 1$ were generated using loop-out mutagenesis with a QuickChange site-directed mutagenesis kit (Stratagene, La Jolla, CA, USA).

\section{Transient Transfections and Luciferase Assays}

SV-40 virus-immortalized $\mathrm{mAHR}^{-1-}$ hepatocytes ${ }^{8}$ were transfected using Lipofectamine 2000 according to the manufacturer's protocol.

\section{Antibodies and Protein Blot Analysis}

AHR was detected using mouse monoclonal antibody RPT1 (Affinity Bioreagents). Primary antibodies were detected with biotinylated rabbit anti-mouse antibodies (Jackson Immunoresearch). Biotinylated secondary antibodies were detected using either ${ }^{125}$ I-streptavidin (Amersham Biosciences) or ECL.

\section{RNA Isolation and Real-Time PCR}

RNA was isolated from cells with TRI ${ }^{\mathbb{R}}$ reagent (Sigma) and reverse transcribed with a High Capacity cDNA Archive kit (Applied Biosystems). Quantitative real-time PCR was carried out on iQ systems (BioRad) using iQ SYBR Green 
master mix (BioRad), according to the manufacturer's protocol. Expression values of genes of interest were normalized to that of ribosomal protein L13a (RpL13a) or $\beta$-actin. The sequence of the primers used in real-time PCR is listed in Supplementary Table S1.

\section{Chromatin Immunoprecipitation Assay}

Chromatin immunoprecipitation assays (ChIP) were carried out as described earlier. ${ }^{9}$ Briefly, cells cultured in $150-\mathrm{mm}$ culture dishes were crosslinked with $1 \%$ formaldehyde for $8 \mathrm{~min}$ at $37^{\circ} \mathrm{C}$ and sonicated using a Branson Sonifier 450 to generate fragments of $500-700 \mathrm{bp}$. The sonicated lysate was diluted to two A260 units and $1 \mathrm{ml}$ of this lysate was subjected to immunoprecipitation with the appropriate antibodies given above and protein A sepharose. The level of enrichment of promoter fragments was determined by PCR or real-time PCR. The Saa3 primers used were 5'GCGCAATCTGGGGAAAGAAGATGT and $5^{\prime}$-TGAGTGGC TTCTGTCCTTTGCTGA (forward and reverse, respectively) for Saa2, $5^{\prime}$-TACTACACCCCAGAAGATTGCCAC and 5'-AG GTGAGAGGAGGCAGGCATTTAT.

\section{siRNA Transfections}

Repression of AHR expression was carried out with siRNA oligos purchased from Dharmacon RNAi Technologies. Approximately, $60 \%$ confluent Huh7 cells were transfected with $120 \mathrm{nM}$ scrambled or anti-AHR oligos using Dharmafect-1 transfection reagent following manufacturer's protocol. Culture medium was changed after $24 \mathrm{~h}$ and the cells were allowed to recover for an additional $12 \mathrm{~h}$ before treatment.

\section{ELISA}

Huh7 cells were treated with 2,3,7,8-tetrachlorodibenzo-pdioxin (TCDD) and interleukins for $10 \mathrm{~h}$ or $24 \mathrm{~h}$ under serum-free conditions. Culture media was analyzed for SAA protein levels using a human SAA ELISA kit purchased from Anogen (Yes Biotech Laboratories Ltd) according to the manufacturer's protocol. The level of SAA in mouse serum was determined using a mouse SAA ELISA kit (Immunology Consultants Lab, Inc. Newberg, OR, USA). Statistical comparison of treatments was carried out using the Student's $t$-test $(\alpha=0.05)$.

\section{DNA Microarray Analysis}

RNA was isolated from $10^{6}$ sorted cells using TRI reagent and further purified with RNeasy columns. RNA integrity was confirmed by Bioanalyzer (Applied Biosystems). Samples were then hybridized to Affy mouse 2.0A genome chips. Labeling, hybridization and washing were carried out at the microarray core facility, the Pennsylvania State University. Data were processed, and significantly altered genes were identified using GeneChip Operating Software. Genes were declared as increased or decreased in AHR and DNA-binding mutant AHR (A78D-AHR) transfected cells, as compared with control transfections.

\section{RESULTS \\ Identification of DNA-binding Independent Effects Mediated by the AHR}

The established mechanism of AHR function involves binding of the AHR-ARNT heterodimer to DNA bearing the DRE sequence. To investigate the possibility of a DNA-binding independent manner of AHR function, simian virus 40 (SV40)-immortalized AHR null mouse hepatocytes were transfected with either the AHR or DNA-binding defective mutant (A78D) AHR-expressing plasmid or control vector. The A78D-AHR mutant has earlier been shown to bind ligand, translocate to the nucleus and heterodimerize with ARNT; yet, it fails to bind DNA at its response element. ${ }^{10}$ Green fluorescent protein (GFP)-expressing plasmid was cotransfected along with AHR plasmids in a ratio of 1:3 and a high level of transfection efficiency was obtained (Supplementary Figure S1a). GFP-expressing transfected cells were subjected to FACS and RNA, and protein was isolated. AHR expression was confirmed by Western blot (Figure 1a) and the RNA was used for microarray experiments. Single samples were analyzed on individual DNA microarrays. Data analysis was targeted to identify the subset of genes altered in WT-AHR as well as A78D-AHR transfected cells, but not in the control. Multiple APR genes were identified to be repressed by the wild-type and DNA-binding defective mutant AHR (Table 1). Maximum repression was observed for Saa3 mRNA, which was selected for further analysis.

\section{Generation and Characterization of an AHR Heterodimerization Mutant}

It is important to examine whether heterodimerization of AHR and ARNT is essential for the DNA-independent effects of AHR. An AHR heterodimerization mutant $(\Delta \mathrm{H} 1-\mathrm{AHR})$ was constructed by deleting the DNA sequence that encodes for amino acids 43-51, which encompass helix-1 of the helixloop-helix domain (Figure 1b). Immunoprecipitation of HAtagged ARNT failed to co-precipitate the $\triangle \mathrm{H} 1$-AHR, showing the inability of this mutant to heterodimerize with ARNT in contrast to WT-AHR (Supplementary Figure S2a). Consequently, $\Delta \mathrm{H} 1$-AHR was unable to drive the expression of DRE-driven luciferase in Cos-1 cells (Supplementary Figure $\mathrm{S} 2 \mathrm{~b}$ ), as well as that of endogenous Cyp1a1 mRNA in BP-8 cells, a rat hepatoma-derived cell line deficient in AHR (Supplementary Figure S2c). However, a photoaffinity ligand-binding assay showed that $\Delta \mathrm{H} 1-\mathrm{AHR}$ was still capable of binding ligand as efficiently as WT-AHR (Supplementary Figure S2d). TCDD treatment of yellow fluorescent protein (YFP)-tagged $\triangle \mathrm{H} 1-\mathrm{AHR}$ and WT-AHR transfected Cos-1 cells showed that $\Delta \Delta \mathrm{H} 1-\mathrm{AHR}$ is capable of translocating into the nucleus on ligand activation (Supplementary Figure S2e). Thus, the $\Delta \mathrm{H} 1$-AHR is selectively deficient in its ability to heterodimerize with ARNT and drive classical DRE-dependent gene expression. 

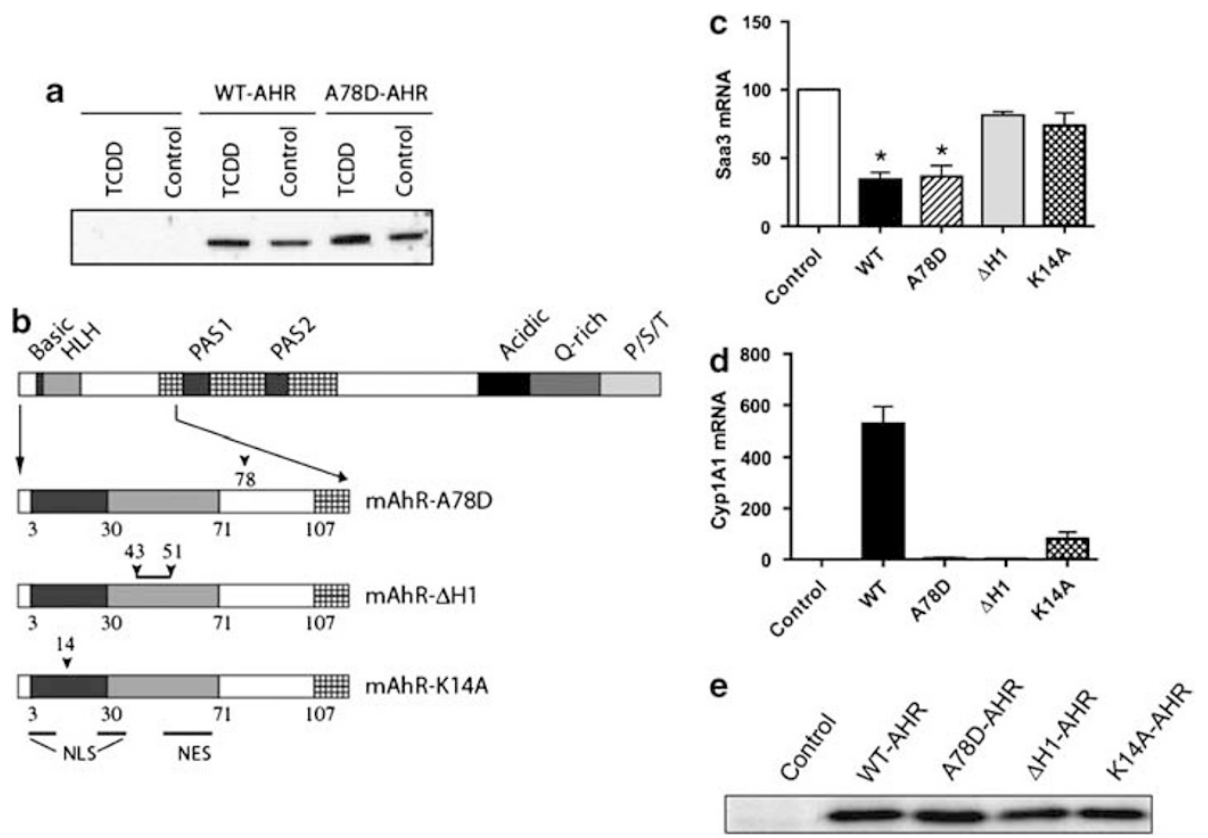

Figure 1 Functional dissociation of the AHR function involved in Saa3 repression. (a) Western blot analysis of WT-AHR and A78D-AHR protein expression in SV40-immortalized AHR-null mouse hepatocytes transfected with a combination of GFP and WT-AHR/A78D-AHR/control vector in a ratio of 1:3, using Lipofectamine2000 transfection reagent. Cells were sorted for GFP expression using FACS analysis. (b) Schematic representation of murine WT-AHR domains and the deletion/mutation (arrowheads) for each AHR mutant. (c and d) Real-time PCR on RNA isolated from SV40-immortalized AHR-null hepatocytes transfected with WT-AHR or various AHR mutants for $24 \mathrm{~h}$. (e) Western blot analysis of the WT-AHR and AHR mutants expressed in experiment depicted in panels $\mathrm{c}$ and d. Data represent mean induction \pm s.e.m. ( $n=3$ /treatment group) and were analyzed by one-way ANOVA to determine significance $\left({ }^{*} P<0.05\right)$. WT, wild type; A78D, DNA-binding mutant; $\Delta \mathrm{H} 1$, heterodimerization mutant; $\mathrm{K} 14 \mathrm{~A}$, nuclear localization mutant.

\section{Saa3 Repression Requires AHR Heterodimerization and Nuclear Translocation}

The conventional AHR pathway requires nuclear translocation and heterodimerization with ARNT. An earlier described K14A-AHR mutant, incapable of translocating to the nucleus, ${ }^{11}$ and the $\Delta$ H1-AHR mutant (Figure 1b) were expressed in SV40-immortalized AHR null cells along with GFP plasmid. Saa3 expression was repressed by the WT-AHR and A78D-AHR, but not by K14A-AHR and $\triangle \mathrm{H} 1$-AHR (Figure 1c). Thus, DNA-binding independent gene regulation by AHR seems to require nuclear translocation and heterodimerization. As expected, Cyp1a1, the prototypic AHR target gene, was induced in the cells transfected with WT-AHR, but not with A78D-AHR or $\triangle \mathrm{H} 1$-AHR (Figure 1d). K14AAHR minimally induced Cyp1a1; however, this may be because of overexpression. It should be noted that activation of AHR by TCDD did not alter the extent of Saa 3 repression in SV40-immortalized AHR null hepatocytes (data not shown).

\section{Saa3 Repression Under Different Experimental Conditions}

The AHR-mediated Saa3 repression observed in immortalized AHR null cells was confirmed in other model systems. Saa 3 transcription was induced in Hepalc1c7 cells, a mouse hepatoma-derived cell line, by treatment with different pro-inflammatory cytokines such as IL1B, IL6, tumor necrosis factor- $\alpha$ (TNFA) or a combination of IL1B and IL6
(Figure $2 \mathrm{a}$ and $2 \mathrm{~b}$ ). Activated AHR repressed the induction of Saa3 by $\sim 50 \%$ for each cytokine treatment. AHR liganddependent repression of Saa 3 induction by AHR may provide an interesting therapeutic approach for chronic inflammatory diseases. However, it is essential to confirm that Saa3 repression is not limited to only high doses of an AHR ligand. To this end, repression of cytokine-induced Saa 3 was studied with decreasing doses of TCDD in Hepalclc7 cells. TCDD was able to effectively repress $\mathrm{Saa} 3$ even at the lowest dose tested (200 pM) (Figure 2e). Also, Hepalclc7 cells were treated with different AHR ligands to determine if Saa3 repression was a TCDD-specific effect. The established AHR ligands, benzo(a)pyrene ( $\mathrm{B}(\mathrm{a}) \mathrm{P}), \beta$-naphthoflavone $(\beta-\mathrm{NF})$, $\alpha$-naphthoflavone $(\alpha-\mathrm{NF})$ and M50354 were all able to repress Saa3 induction (Figure 2c). M50354 is a recently described AHR agonist compound capable of attenuating atopic allergic responses. ${ }^{12}$ It is interesting to note that all ligands tested were effective at repressing Saa3, whereas TCDD was far more effective at inducing CYP1A1 (Figure 3d). These results would support the concept that an AHR ligand may be found that is highly selective in eliciting a gene repression response.

\section{AHR-Mediated Saa3 Repression is a Direct Transcriptional Effect}

To ascertain that AHR directly effects the transcription of Saa3, Hepa1c1c7 cells were pretreated with cycloheximide, a 
Table 1 Genes regulated by transiently expressed A78D-AHR or WT-AHR in immortalized AHR-null murine hepatocytes compared with control transfected cells

Gene title

Aryl-hydrocarbon receptor

Trimethyllysine hydroxylase, epsilon

LIM domain containing preferred translocation partner in lipoma

Acidic (leucine-rich) nuclear phosphoprotein 32 family, member A

Denticleless homolog (Drosophila)

DNA segment, Chr 9, ERATO Doi 306, expressed

PREDICTED: LIM domain only 7 (Mus musculus), mRNA sequence

Germ cell-less homolog (Drosophila)

Zinc-finger protein 207

WD repeat domain 26

Protein tyrosine phosphatase, receptor type, J

RIKEN cDNA 3300001H21 gene

Zinc-finger protein 179

Ceruloplasmin

Procollagen, type $\mathrm{VI}$, alpha 1

Matrilin 2

Interferon, $\alpha$-inducible protein 27

Vanin 3

\section{Transferring}

Procollagen, type $\mathrm{VI}$, alpha 2

Procollagen, type VI, alpha 2

Myxovirus (influenza virus) resistance 1

Complement component factor $h$

Complement component 1 , s subcomponent

Slit homolog 3 (Drosophila)

Kruppel-like factor 10

lipocalin 2

Lipopolysaccharide binding protein

Serine (or cysteine) peptidase inhibitor, clade A, member 3M

Proteoglycan 4 (megakaryocyte stimulating factor, articular superficial zone protein)

\section{Complement component 3}

FBJ osteosarcoma oncogene

Serine (or cysteine) peptidase inhibitor, clade $\mathrm{A}$, member $3 \mathrm{~N}$

STEAP family member 4

Serine (or cysteine) peptidase inhibitor, clade A, member $3 G$

Serum amyloid A 3
Gene symbol

Ratio A78D vs control Ratio WT vs control

Ahr

Tmlhe

2.6

Lpp

Anp32a

Dtl

D9Ertd306e

Lmo7

$\mathrm{GCl}$

Zfp207

Wdr26

Ptprj

3300001H21Rik

Zfp179

Cp

Col6a1

Matn2

Ifi27

Vnn3

Trf

Col6a2

Col6a2

Mx1

Cfh

C1s

Slit3

Klf10

Len2

Lbp

Serpina3m

Prg4

C3

Fos

Serpina3n

Steap4

Serpina3g

Saa3

\section{6}

2.1

1.7

1.7

1.6

1.5

1.5

1.4

1.4

1.4

1.4

0.7

0.7

0.7

0.7

0.7

0.7

0.7

0.7

0.7

0.7

0.7

0.7

0.7

0.7

0.7

0.6

0.6

0.6

0.6

0.6

0.6

0.5

0.5

0.5

0.4
2.7

2.2

1.8

1.6

1.6

1.7

1.6

1.6

1.6

1.7

0.6

0.6

0.5

0.6

0.6

0.5

0.6

0.6

0.6

0.6

0.6

0.6

0.5

0.6

0.6

0.6

0.5

0.6

0.5

0.5

0.4

0.5

0.4

0.6

0.4

Genes in bold denote an acute-phase response gene.

translation inhibitor. Though cycloheximide treatment elevated the constitutive level of Saa3 expression, it did not alter its repression by AHR activation (Figure $2 \mathrm{~g}$ ). This indicates that AHR-mediated Saa3 repression is a direct effect and not secondary to changes in the expression of another protein. Gene repression can be mediated by a decrease in transcription rate or by alteration of mRNA stability. After challenging with TCDD and ILB/IL6, Hepalc1c7 cells were 

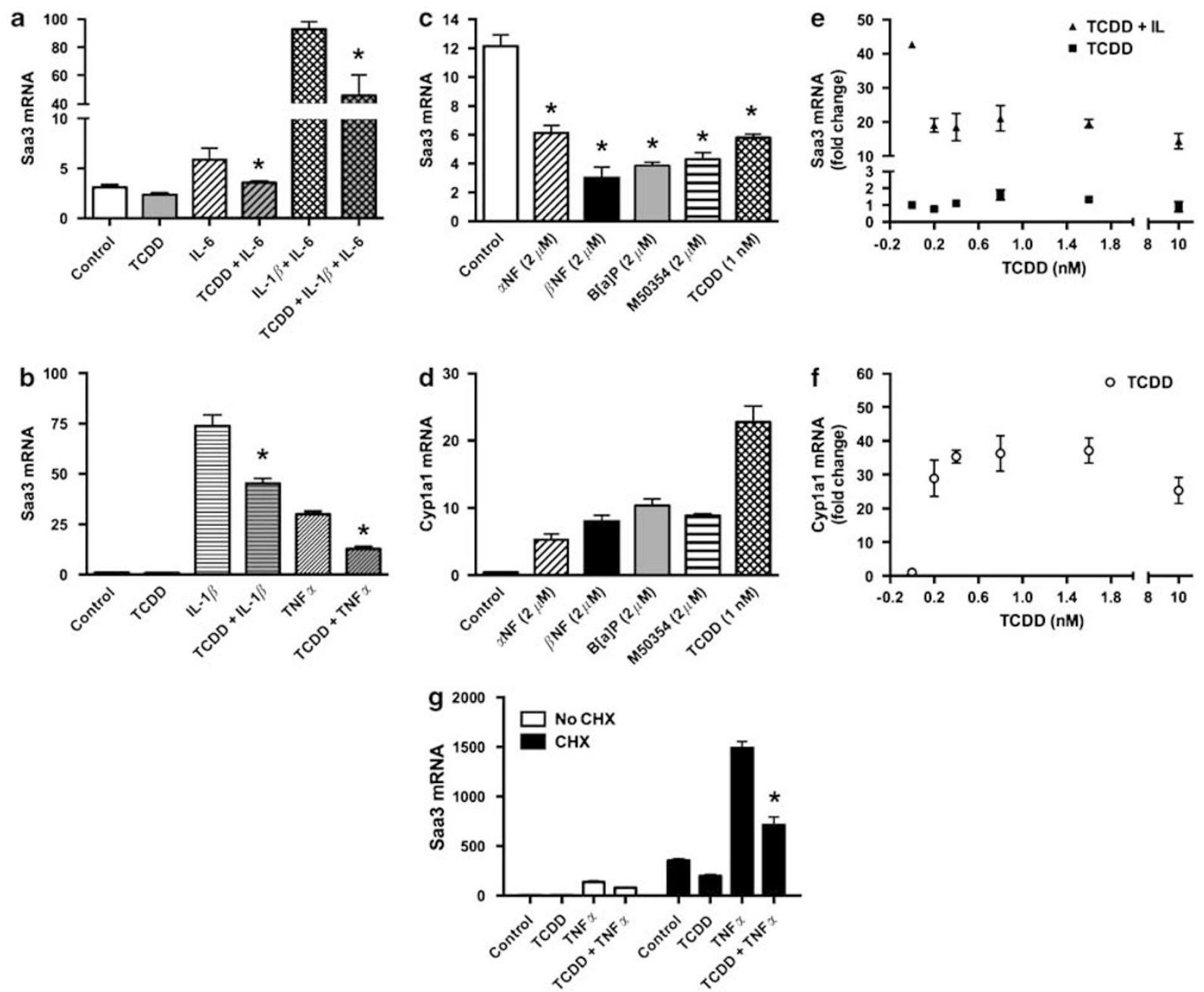

Figure 2 AHR directly represses Saa3 transcription in a dose-responsive and ligand-dependent manner. (a and b) AHR represses Saa3 induction by various cytokines. Hepa1c1c7 cells were treated with $10 \mathrm{nM}$ TCDD or vehicle control. After $30 \mathrm{~min}$, cells were treated with $2 \mathrm{ng} / \mathrm{ml}$ IL1B, IL6, TNFA or a combination of IL1B and IL6 for an additional $6 \mathrm{~h}$. (c and d) Various classes of AHR ligands can suppress Saa3. Hep1c1c7 cells were treated with different AHR ligands at the described doses for 30 min before interleukin (IL1B + IL6, $2 \mathrm{ng} / \mathrm{ml}$ each) treatment. Saa3 mRNA (c) and Cyp1a1 mRNA (d) were measured by real-time PCR. (e and $\mathbf{f}$ ) Analysis of TCDD dose-response of AHR-mediated Saa3 repression. Hepa1c1c7 cells treated with increasing doses of TCDD ( $0.2 \mathrm{nM}$ to $10 \mathrm{nM}$ ) for $30 \mathrm{~min}$ before interleukin (IL1B + IL6, $2 \mathrm{ng} / \mathrm{ml}$ each) treatment. (e) Closed triangles represent repression of IL-induced Saa3 mRNA by various doses of TCDD, as determined by real-time PCR. Closed squares represent uninduced Saa3 mRNA levels, as a control. (f) TCDD-driven Cyp1a1 mRNA induction, as measured by real-time PCR. (g) AHR-mediated Saa3 repression is because of direct transcriptional inhibition. Real-time PCR on RNA from Hepa1c1c7 cells treated first with (black bars), or without (open bars), the translational inhibitor-cycloheximide $(10 \mu \mathrm{g} / \mathrm{ml})$ for $30 \mathrm{~min}$, then with TCDD $(10 \mathrm{nM})$ for $30 \mathrm{~min}$ and finally with TNFA for $6 \mathrm{~h}$. Data represent mean induction \pm s.e.m. $\left(n=3 /\right.$ treatment group) and were analyzed to determine significance $\left({ }^{\star} P<0.05\right)$.

treated with Actinomycin D, a transcription inhibitor, and the level of Saa3 mRNA was assessed over $4 \mathrm{~h}$. The decay rate of Saa3 mRNA was not significantly altered by AHR activation over the time period examined (data not shown).

\section{AHR Activation Represses Other Saa Family Member Genes}

All members of the SAA family are upregulated simultaneously in an APR. Hence, we examined the effect of AHR activation on the expression of Saa1 and Saa2 in Hepalclc7 cells (Figure 3a and b). Cytokine-mediated induction of both Saa1 and Saa2 was repressed by AHR activation by 75 and $85 \%$, respectively. This is significant as Saa1 and Saa2 are the major hepatic serum amyloid isoforms. It is interesting to note that Saa1 and Saa2 did not seem to be repressed in the earlier microarray results from WT-AHR or A78D-AHR transfected SV40-immortalized mouse hepatocytes, the reason for which is not clear.

\section{Saa Repression is AHR-Dependent}

AHR-deficient or AHR-expressing primary hepatocytes were isolated from $A h r^{f x / f x} C r e^{A l b}$ (hepatocyte-specific conditional AHR null $)^{13}$ or C57BL6/J mice, respectively. Saa transcription was highly induced in these cells by IL1B/IL6 treatment. TCDD was able to restrict the induction of Saa1 and Saa2 in AHR-expressing (Figure $3 \mathrm{c}$ and d), but not in AHR-deficient, 

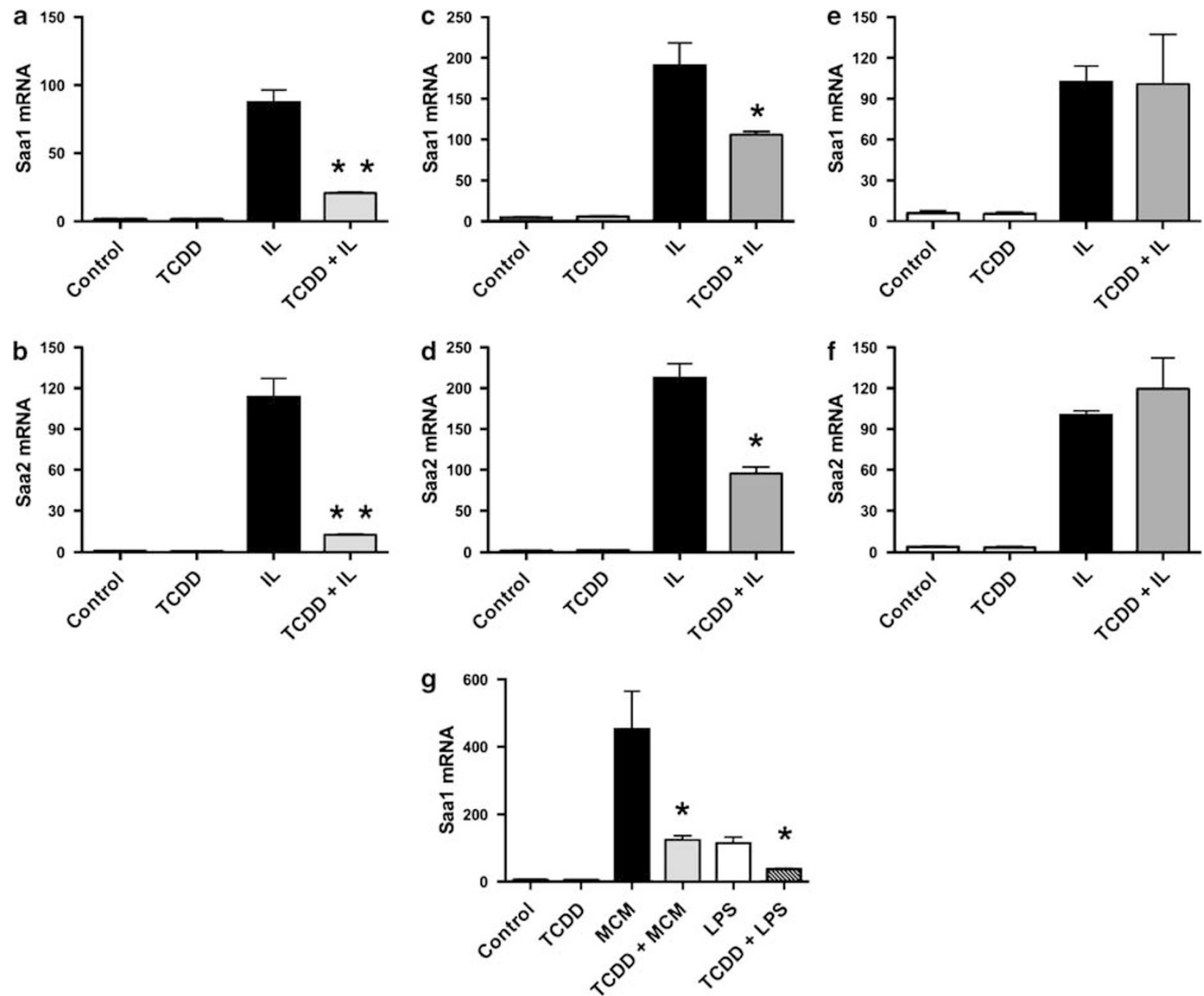

Figure 3 AHR activation represses gene expression of several Saa family members. (a and $\mathbf{b}$ ) Real-time PCR on RNA from TCDD (10 nM, 30 min) followed by interleukin ( $2 \mathrm{ng} / \mathrm{ml}$ each of IL1B and IL6) treated Hepa1c1c7 cells. Effect of AHR activation on induction of other SAA family members, Saa1 (a) and Saa2 (b), was determined. Data represents the mean \pm s.d. of triplicate measurements. Experiment was repeated thrice with similar results. (c and d) Real-time PCR on RNA from primary mouse hepatocytes treated with TCDD (10 nM for $30 \mathrm{~min}$ ) followed by interleukin ( $2 \mathrm{ng} / \mathrm{ml}$ each of IL1B and IL6) for 24 h. Before treatment, cells were transferred to $\alpha$-MEM with $1 \mathrm{mg} / \mathrm{ml}$ bovine serum albumin for $24 \mathrm{~h}$. Repression of Saa1 (c) and Saa2 (d) mRNA was measured. (e and $\mathbf{f}$ )

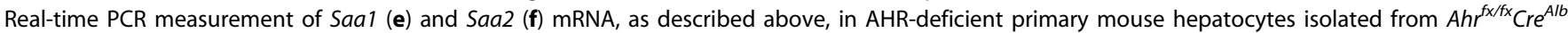
mice. (g) Primary murine bone marrow cells were cultured to promote differentiation into macrophages, as outlined in the text. After a 3-day LPS challenge, the conditioned media was collected from macrophage-containing plates (MCM-macrophage conditioned media) and used to treat Hepa1c1c7 cells for $6 \mathrm{~h}$ after TCDD (10 nM, $30 \mathrm{~min})$ pre-treatment. 'LPS' refers to LPS-spiked media that was maintained under similar culture conditions in the absence of any cells, and thus was devoid of any cytokines secreted by macrophages. Saa1 mRNA levels were determined by real-time PCR. Data represent mean induction \pm s.e.m. ( $n=3 /$ treatment group) and were analyzed to determine significance $\left({ }^{\star} P<0.05 ;{ }^{*} P<0.01\right)$.

hepatocytes (Figure $3 \mathrm{e}$ and $\mathrm{f}$ ). This, along with the observation that AHR transfection in AHR null cells is required for suppressing Saa3 (Figure 1c), clearly establishes that AHR is essential for Saa repression by TCDD.

\section{AHR Can Repress Saa Induction Mediated by Complex Inflammatory Medium}

Different cytokines can have counter-regulatory effects on various aspects of an inflammatory response. Thus, it is possible that IL1B- and IL6-mediated Saa induction might not simulate the exact response obtained with a combination of cytokines, as expected in an inflammatory response in vivo. To confirm the ability of AHR to repress Saa induction under such circumstances, primary bone marrow cells were isolated from C57BL6J mice and were cultured to promote differentiation into macrophages. After a 3-day LPS challenge, the conditioned culture medium was collected from the macrophages and used to treat Hepalclc7 cells. To differentiate the effect of secreted cytokines from those of LPS, LPS-containing culture medium was incubated in the absence of macrophages and used as a control. AHR activation was able to repress the induction of Saal in response to the macrophage-conditioned media or LPS alone (Figure 3g). Similar results were obtained on examining Saa2 repression 

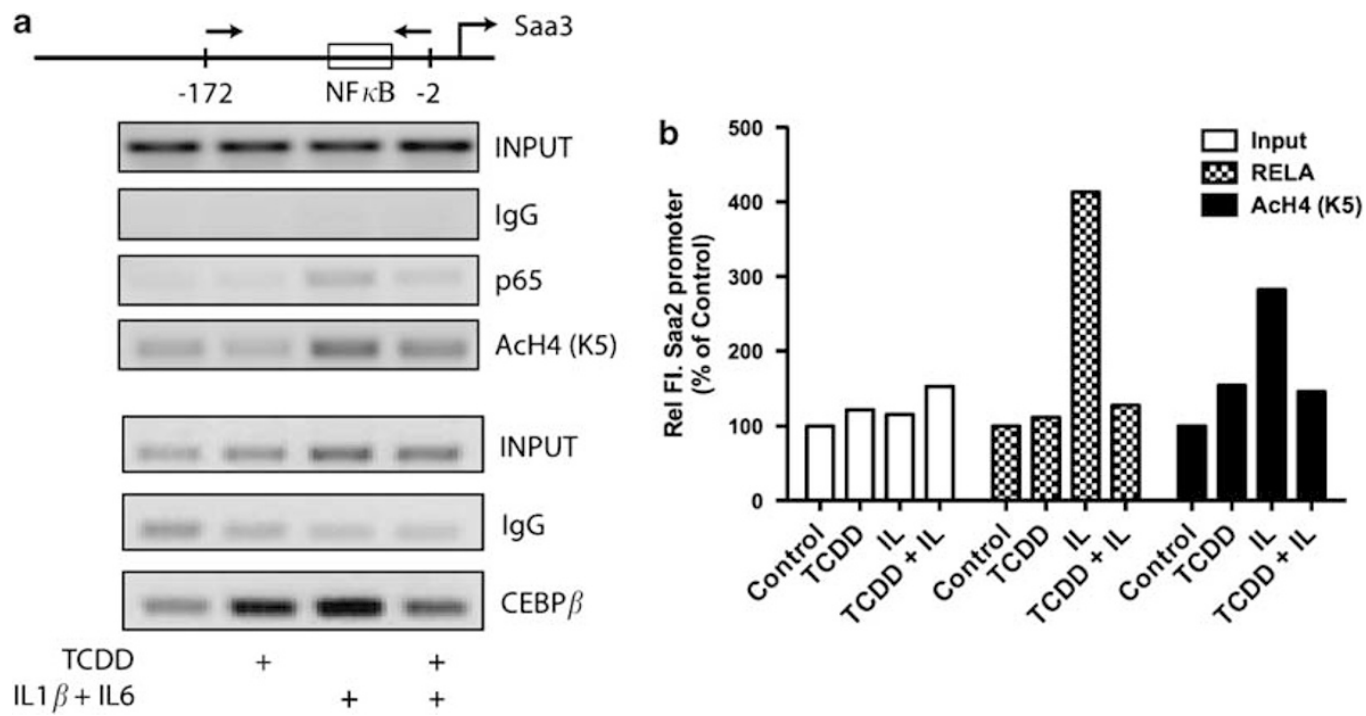

Figure 4 AHR directly represses Saa transcription. (a and b) ChIP assay to determine the effect of AHR activation on Saa2 and Saa3 promoters. Hepa1c1c7 cells were treated with TCDD ( $10 \mathrm{nM}$ for $30 \mathrm{~min}$ ) before interleukin treatment ( $2 \mathrm{ng} / \mathrm{ml}$ each of IL1B and IL6 for 20 min). Immunoprecipitation was carried out with antibodies for RELA and acetylated histones (K5). Changes at the Saa3 promoter were assessed by PCR (a), whereas changes at Saa2 promoter were analyzed by real-time PCR (b). Data represent one of three independent experiments.

by TCDD (data not shown). This shows AHR's ability to repress Saa induction under a physiologically attainable concentration/combination of cytokines.

Mechanistic Insights into AHR-mediated Saa Repression The facts that AHR directly represses Saa 3 and that the K14A-AHR (nuclear localization) mutant failed to repress Saa3 induction, suggest that AHR likely affects the formation of a transcription complex within the nucleus and perhaps at the Saa promoters. ChIP assays in Hepalclc7 cells show that activated AHR seems to reduce the presence of the RELA (p65) subunit of NF- $\kappa \mathrm{B}$ at the Saa3 and Saa2 promoters in response to interleukin treatment (Figure $4 \mathrm{a}$ and $\mathrm{b}$ ). In addition, C/EBP $\beta$ presence on the SAA3 promoter after cytokine treatment was greatly inhibited after TCDD cotreatment (Figure 4a). AHR has earlier been shown to physically interact with RELA, ${ }^{14}$ which might then contribute to preventing RELA recruitment to Saa promoters in response to IL1B/IL6 treatment. ChIP with an acetylated histone 4 antibody showed that AHR activation also reduced histone acetylation at Saa2 and Saa3 promoters (Figure 4a and b).

AHR-Mediated Suppression Extends to Other APR Genes After confirming the repression of Saal and Saa2 in primary mouse hepatocytes, expression of other APR genes was also examined by real-time PCR (Figure $5 \mathrm{a}-\mathrm{f}$ ). AHR activation was able to repress induction of a number of acute-phase genes, including CRP, LPS-binding protein (LBP), haptoglobin, $\alpha$-2-macroglobulin and $\alpha$-1-acid glycoprotein-1. This suggests that AHR represses the APR through a common transcriptional regulatory mechanism.

\section{AHR Activation In Vivo Leads to Attenuation of Cytokine-Mediated Acute-Phase Response}

To test whether activation of the AHR leads to repression of cytokine-mediated APR, we reasoned that continual exposure to an AHR ligand would be more effective, thus a dietary route of exposure was chosen. After a preliminary dose-response experiment with dietary $\beta$-NF indicated that $0.4 \mathrm{~g}$ of $\beta-\mathrm{NF} / \mathrm{kg}$ yielded about $10 \%$ of the Cypla1 inducibility observed at higher doses of $\beta$-NF in mice, BNF concentration was chosen for subsequent experiments (data not shown). C57BL6/J mice were fed a semi-purified control diet or a diet containing $0.4 \mathrm{~g}$ of $\beta-\mathrm{NF} / \mathrm{kg}$ overnight. Mice were then i.p. injected with IL1B and IL-6, and after $5 \mathrm{~h}$ the liver RNA was isolated. The level of Cyp1a2 mRNA induction was measured in C57BL6/J and Ahr-null mouse liver in the presence and absence of IL1B/IL-6 as a measure of AHR activation (Supplementary Figure S4). These results revealed that $\beta$-NF induced Cyp1A2 mRNA in C57BL6/J mice, indicating that dietary $\beta$-NF effectively induced AHR activity. Real-time PCR analysis revealed that Saa1, Saa2 and Crp mRNA inductions after cytokine treatment were all significantly reduced by the presence of an AHR ligand (Figure 6). In contrast, dietary $\beta$-NF had no effect on cytokine-mediated acute-phase gene expression in Ahr-null mice, indicating that the observed repression in C57BL6/J mice is AHR-mediated (Figure 3S). It is interesting that $\beta$-NF treatment of $A h r$-null mice leads to an increase in cytokinemediated induction of certain APR genes (eg $L p b$ ). As expected, IL1B/IL6 exposure in mice leads to the induction of Il-8 and Nfkbia mRNA in the liver, two genes regulated by inflammatory signaling (Figure $6 \mathrm{e}-\mathrm{f}$ ). In addition, $\beta$-NF failed to significantly influence the level of induction of $\mathrm{Il}-8$ 

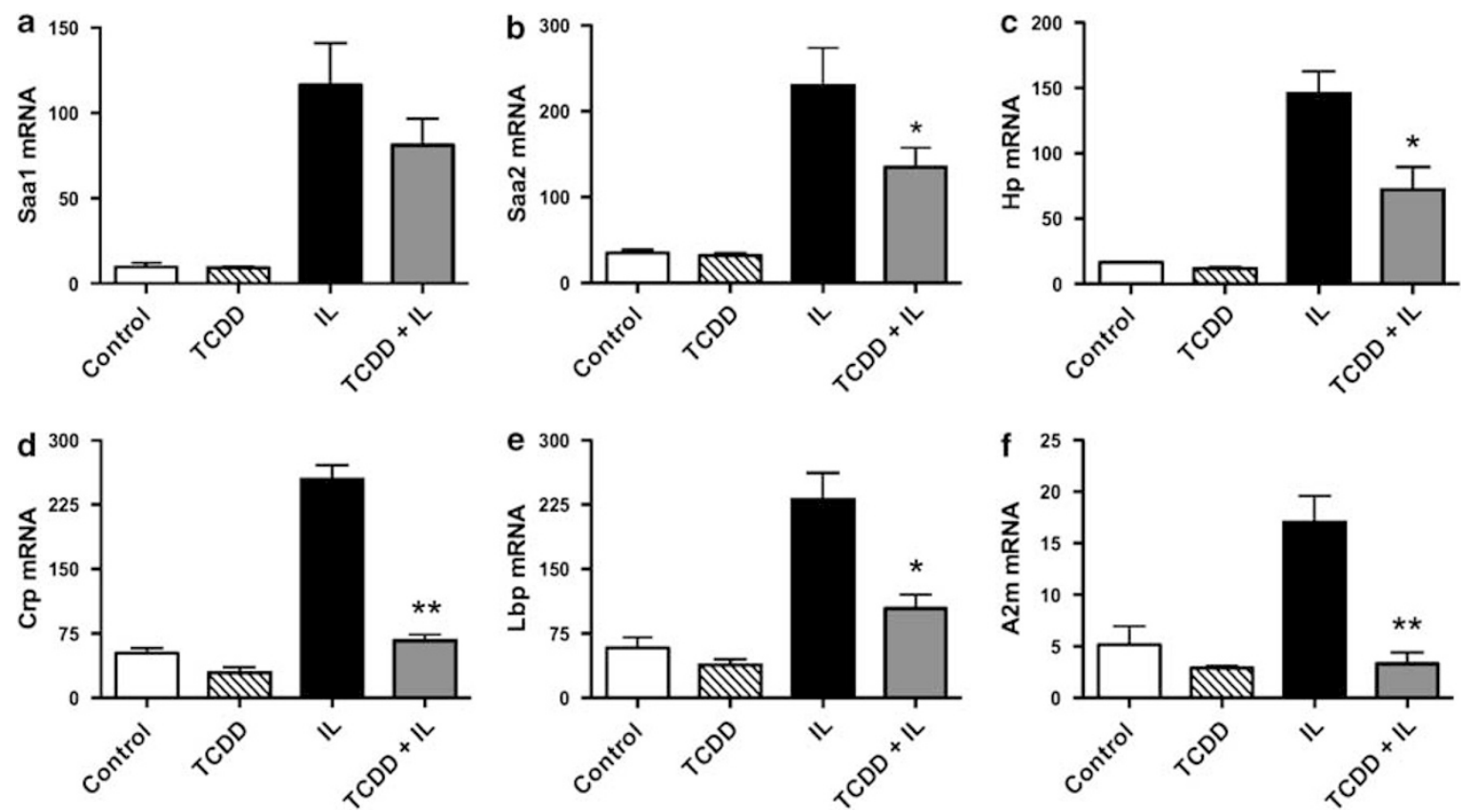

Figure 5 AHR activation represses a battery of APR genes. Real-time PCR on RNA from primary mouse hepatocytes treated with TCDD (10 nM, $30 \mathrm{~min}$ ) followed by interleukin ( $2 \mathrm{ng} / \mathrm{ml}$ each of IL1B and IL6) for $24 \mathrm{~h}$. Repression of various APR genes was assayed.. Data represent mean induction \pm s.e.m. ( $n=3$ / treatment group) and were analyzed to determine significance $\left({ }^{*} P<0.05 ;{ }^{*} P<0.01\right)$. CRP, C-reactive protein; LBP, LPS-binding protein; A2 $\mathrm{m}, \alpha-2$ macroglobulin; $\mathrm{Hp}$, haptoglobin.

and Nfkbia (commonly known as $\mathrm{I} \kappa \mathrm{B} \alpha$ ) mRNA, suggesting that the AHR's ability to alter inflammatory gene regulation is gene context specific. However, Il8 mRNA levels did show a non-statistically significant repressed response to $\beta$-NF exposure.

\section{AHR-Mediated Repression of SAA is Observed in Human Huh7 Cells}

Another important question to address is whether human cells would elicit a similar response to AHR activation in the presence of cytokines. SAA3 is not expressed in human liver, ${ }^{15}$ whereas $S A A 1$ and $S A A 2$ have a very high sequence similarity, thus making it difficult to design unique primer set for detecting $S A A 2$. Hence, SAA1 mRNA levels were monitored to assess the effect of AHR activation on the APR. Huh7 cells, a human hepatocarcinoma-derived cell line, were treated with vehicle or TCDD to activate the AHR, followed by treatment with human IL1B and IL6. Under these conditions, activation of AHR repressed SAA1 mRNA induction by $75 \%$ (Figure $7 \mathrm{a}$ ). Changes in the level of secreted SAA protein were determined by ELISA and were found to mimic changes in mRNA (Figure 7b). As it is not possible to differentiate between different SAA family members by ELISA, this repression of SAA reflects the changes in the levels of all secreted SAA family members.

Although TCDD exerts its effects almost exclusively through the AHR, we wished to confirm that the observed TCDD-mediated Saal repression in human cells is indeed AHR dependent. Repression of AHR expression in Huh7 cells was accomplished using $A H R$ siRNA oligonucleotides. As expected, diminished AHR expression resulted in a loss of $S A A 1$ repression with TCDD treatment (Figure $7 \mathrm{c}$ and e). AHR repression was verified by the loss of its ability to induce a transcriptional target gene, CYP1A1 (Figure 7d). It is interesting that the loss of $\mathrm{AHR}$ resulted in an enhanced induction of $S A A 1$ with IL1B/IL6 treatment (Figure 7c). To confirm that this was not an off-target effect of the $A H R$ siRNA oligo sequence, a second anti-AHR siRNA oligo was transfected into Huh7 cells by electroporation. Loss of AHR expression blocked TCDD-mediated repression of cytokine induced SAA1 expression (Figure 7e). Repression of AHR expression by this second $A H R$ siRNA also resulted in enhanced SAA1 induction by IL1B/IL6 treatment (Figure 7f). This suggests that AHR may function to constitutively suppress the level of $S A A 1$ transcription.

Whether AHR-mediated repression of inflammatory genes is a universal phenomenon or a promoter-specific effect was examined. Two known NF- $\kappa \mathrm{B}$-regulated genes, $I l-8$ and Nfkbia, were induced by IL1B/IL6 and both remained unaffected on co-treatment with TCDD (data not shown). Thus, AHR-mediated repression of cytokine-mediated induction of acute phase gene expression is context specific and does not seem to occur at every target gene regulated by $\mathrm{NF} \kappa \mathrm{B}$.

\section{DISCUSSION}

A dysregulated inflammatory/immune response seems to be the underlying cause of many diseases, such as multiple 


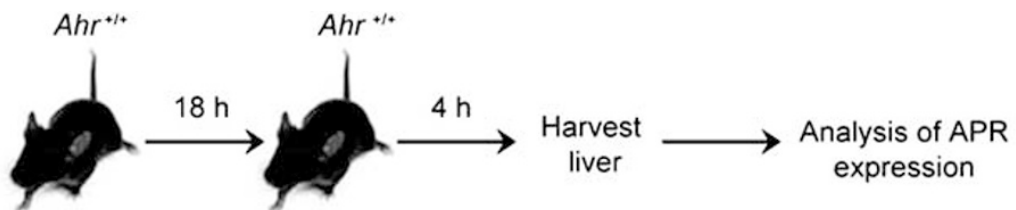

Purified diet

or $0.4 \mathrm{~g} / \mathrm{kg} \beta$-NF $\quad 10 \mu \mathrm{g} / \mathrm{kg} \mathrm{IL-1} \beta / \mathrm{IL}-6$
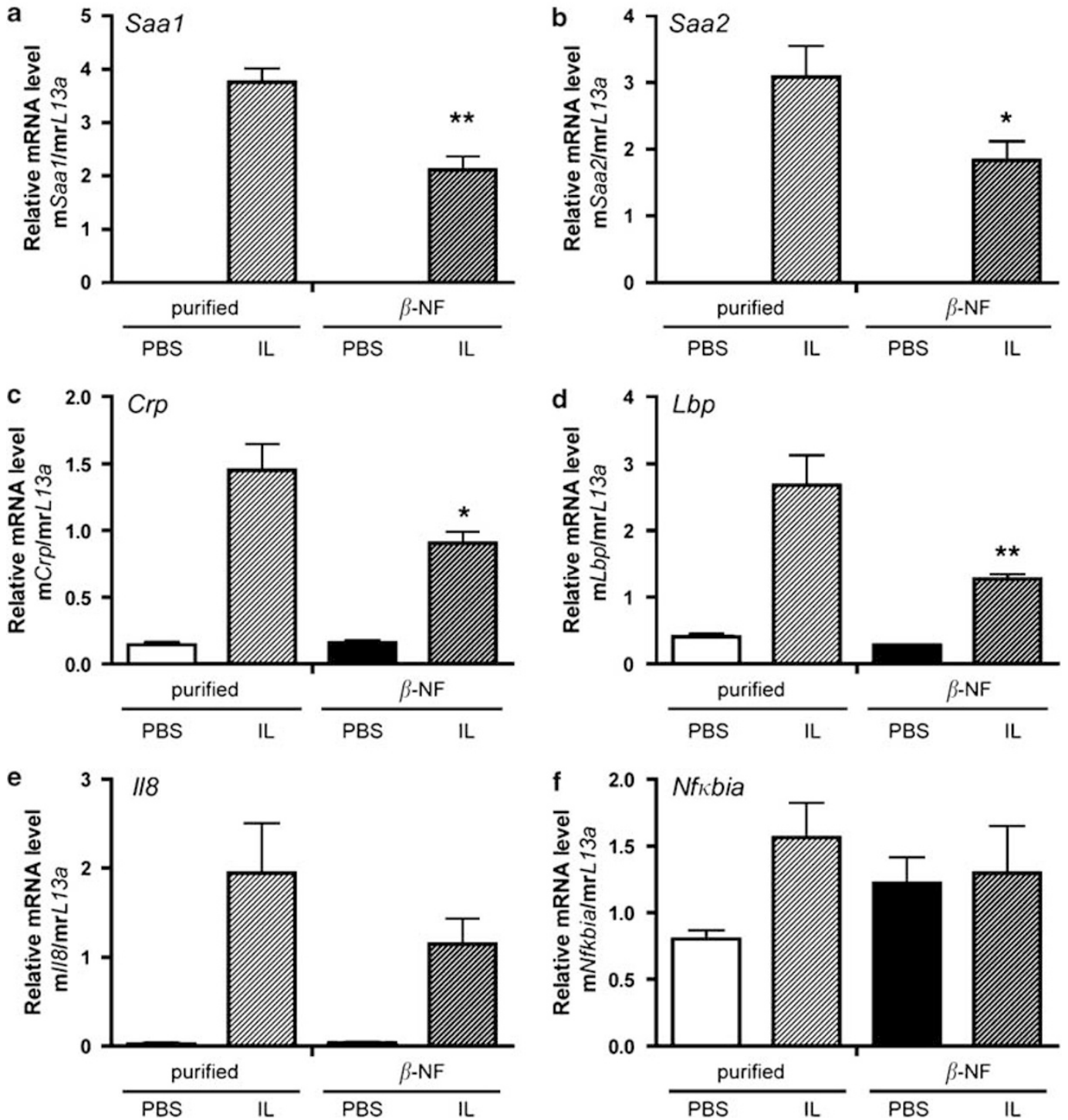

Figure $6 \beta$-NF attenuates cytokine-mediated APR expression in vivo. Female C57B6/J mice were given ad libitum access to purified chow $\pm 0.4 \mathrm{~g} / \mathrm{kg} \beta$-NF for $18 \mathrm{~h}$. After $18 \mathrm{~h}$ mice were given i.p. injection of vehicle (PBS) or $10 \mathrm{mg} / \mathrm{kg}$ murine IL1B/IL6, as indicated. At $4 \mathrm{~h}$ after i.p. injection, mice were killed and hepatic tissue was harvested for RNA isolation and subsequent quantitative PCR analysis of APR and pro-inflammatory genes Saa1, Saa2, Crp, Lbp, II-8 and Ikb (Nfkbia) was carried out (a-f). Data represent mean induction \pm s.e.m. ( $n=3 /$ treatment group) and were analyzed by one-way ANOVA to determine significance $\left({ }^{*} P<0.05 ;{ }^{*} P<0.01\right)$.

sclerosis, asthma, lupus and rheumatoid arthritis. An APR dominates the initial reaction to perceived insults and commences a series of biochemical and neuroendocrine changes that facilitate mounting an inflammatory/immune response. APPs largely expressed by the liver serve various tasks in this process. However, persistent activation of the APR has its own perils. Elevated CRP is associated with increased cardiovascular risk and has been proposed to be a better clinical marker of atherosclerosis and related events than lipid levels. ${ }^{16} \mathrm{SAA}$ is an apolipoprotein for high-density lipoproteins 
a
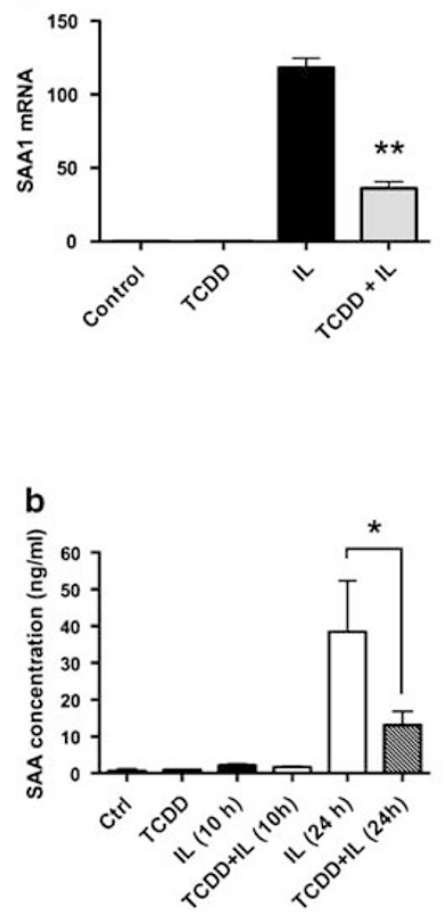

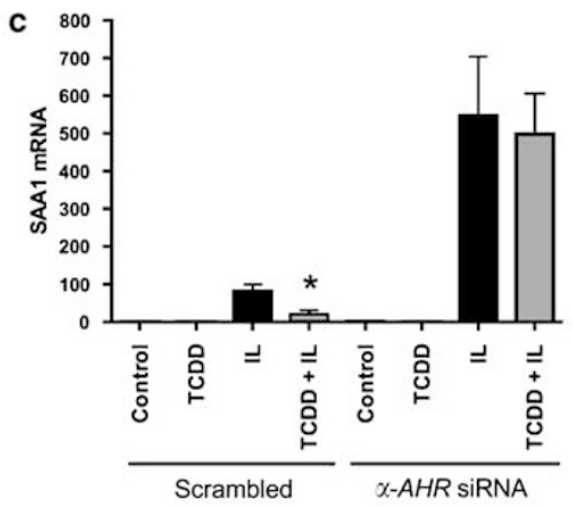

e
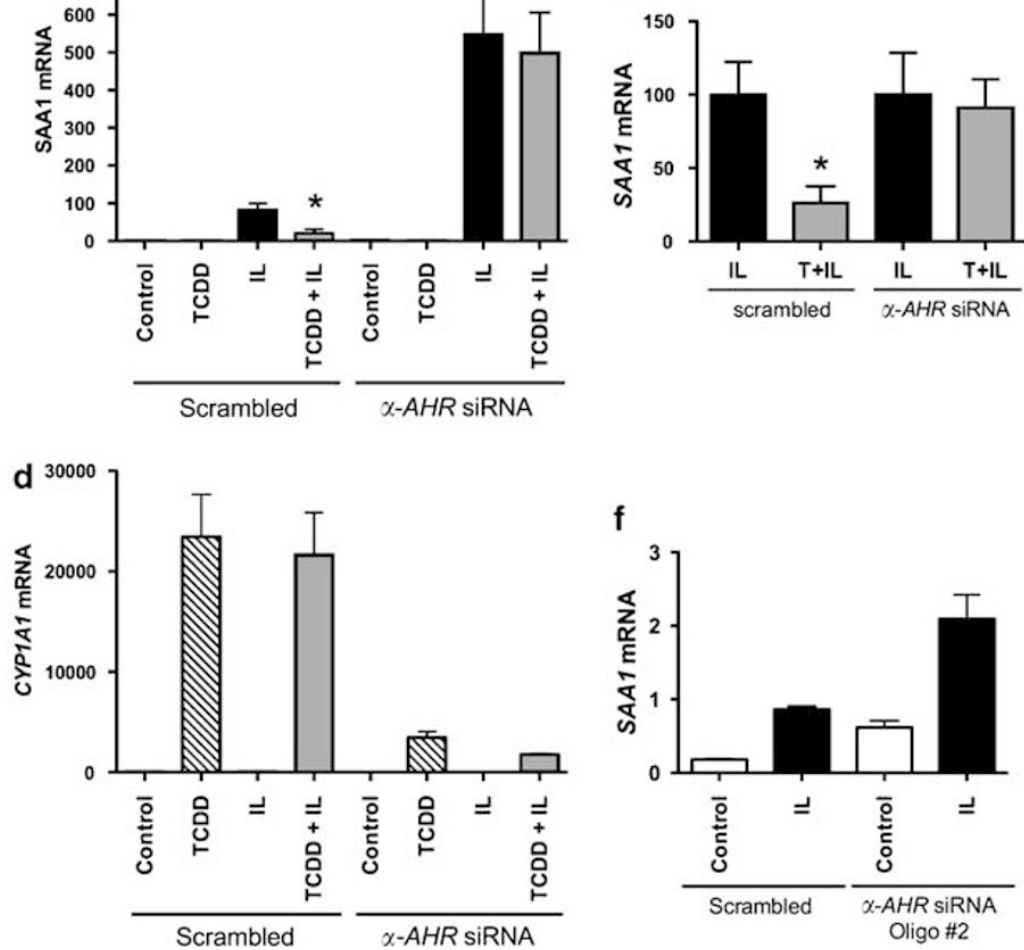

f

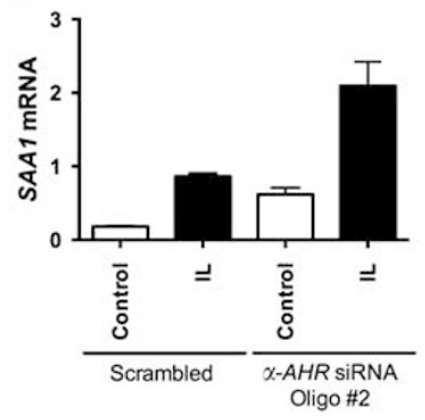

Figure 7 AHR-mediated repression of SAA in human cells. (a) Real-time PCR on RNA from Huh7 cells treated with TCDD (10 nM, $30 \mathrm{~min}$ ) followed by human interleukins ( $2 \mathrm{ng} / \mathrm{ml}$ each of IL1B and IL6) for $6 \mathrm{~h}$. Human SAA1 mRNA abundance was assayed. (b) ELISA to quantify SAA protein secreted by Huh7 cells, treated for $10 \mathrm{~h}$ or $24 \mathrm{~h}$ with TCDD and interleukins. Just before treatment, cells were transferred to serum-free medium. (c and d) siRNA-driven AHR knock down in Huh7 cells. $36 \mathrm{~h}$ after siRNA transfection, cells were treated with TCDD and interleukins, as in (a). SAA1 mRNA (c) and CYP1A1 (d) mRNA levels were determined by real-time PCR. (e) An alternate representation of data from (c). SAA1 induction, on interleukin exposure of scrambled and anti-AHR siRNAtransfected cells, was scaled to 100 units. (f) Real-time PCR to assess SAA1 mRNA induction in Huh7 cells electroporated with a different anti-AHR siRNA oligo (Dharmafect). Data represent mean induction \pm s.e.m. ( $n=3$ /treatment group) and were analyzed to determine significance $\left({ }^{\star} P<0.05 ;{ }^{*} P<0.01\right)$.

and influences cholesterol metabolism leading to enhanced inflammation. Conversely, constant elevation of SAA, and even $\alpha$-2-macroglobulin, leads to extracellular amyloid plaques that interfere with organ function and underlie the pathology of diseases such as Alzheimer's. ${ }^{17}$ In about $5 \%$ of rheumatoid arthritis patients AA amyloid deposition occurs, which can then lead to renal dysfunction and other adverse complications. ${ }^{18}$ Therapies that can selectively reduce circulating SAA levels should be useful in managing amyloidosis in these patients.

Recent studies have shown that SAA can contribute to systemic inflammation. ${ }^{19}$ For example, SAA has been shown to serve as a ligand that activates TLR2, RAGE and FPRL1 receptors, leading to an enhanced inflammatory response. ${ }^{20-22}$ Collectively, signaling through these receptors can lead to activation of MAPKs, p42/44, JNK and p38 kinases, as well as the transcription factors AP- 1 and NF $\kappa$ B. The ability of SAA to activate FPRL1 receptor in synoviocytes can result in synovial hyperplasia as well as endothelial angiogenesis, two common phenotypes observed in rheumatoid arthritis. ${ }^{22}$ It is interesting to note that elevated levels of the AHR have been observed in synovial tissue of rheumatoid arthritis patients, suggesting another possible target tissue for modulating AHR activity. ${ }^{23}$

Transcription of SAA and most other APPs, are primarily regulated by NF- $\kappa$ B, NF-IL6 $(\mathrm{C} / \mathrm{EBP}-\beta)$ and STAT3 ${ }^{24}$ The inhibitory effects of the glucocorticoid receptor (GR) and estrogen receptor (ER) on NF- $\kappa \mathrm{B}$-induced gene transcription has received wide attention. ${ }^{25} \mathrm{NF}-\kappa \mathrm{B}$ signaling allows multiple levels of regulation, which have been utilized by NRs to interact with this pathway. Cytokines engage distinct receptors on the cell surface, leading to recruitment and activation of a family of adapter proteins through various posttranslational modifications. Eventually, signaling from different cytokine receptors converges on phosphorylation-dependent activation of the IKK complex (I $\kappa \mathrm{B}$-kinase complex), which in turn releases NF- $\kappa$ B to translocate into the nucleus. Activated AHR may inhibit any of these cellsurface receptors or the immediate downstream cytoplasmic signaling to repress NF- $\kappa \mathrm{B}$ activity. However, in the context of APR gene regulation, AHR effectively repressed Saa3 mRNA when induced separately by IL1B, IL6 and TNFA. Also, K14A-AHR the nuclear localization mutant, was unable to repress Saa3 mRNA induction. This shows that 
AHR-mediated NF- $\kappa$ B suppression is not because of an effect on upstream cytokine signaling, but is primarily a nuclear phenomenon.

In ChIP assay, activation of AHR diminished cytokineinduced association of the RELA subunit of NF- $\kappa \mathrm{B}$ with its response elements in Saa 2 and Saa3 promoters. Other groups have earlier shown the ability of AHR to physically interact with RELA. ${ }^{14}$ Although a direct physical interaction between the two proteins might certainly explain the reduction in RELA recruitment to Saa promoters, it cannot be the sole mechanism for AHR-NF- $\kappa$ B cross-talk because AHR activation is unable to universally repress NF- $\kappa \mathrm{B}$ driven gene expression (Figure $7 \mathrm{G}$ and $7 \mathrm{H}$ ). Also, we did not observe a significant reduction in RELA or p50 protein levels on AHR activation (data not shown). Yet another possible mechanism could be the ability of the AHR to interact with RelB and bind to RelB-like response elements, as has been observed in U937 macrophages. ${ }^{26}$ However, we have been unable to detect the AHR at the SAA3 promoter by ChIP analysis.

The degree of APR repression observed in mice in this study is not as marked as that observed in cell culture experiments. There may be many reasons for this observation, although we believe that treatment of mice with an AHR agonist will have a dual effect on inflammatory signaling. There are two basic mechanisms that can modulate inflammatory signaling that probably are cell-type specific; the first is the ability of the AHR/ARNT heterodimer to repress gene transcription, which is the subject of this report. The second is the ability of various AHR ligands to enhance inflammatory signaling, apparently through a DRE-mediated mechanism. For example, IL1B and TCDD co-treatment of MCF-7 cells leads to a syngeristic induction of $I l 6$ expression. ${ }^{27}$ The use of an AHR ligand that can effectively dissociate the repressive effects from the DRE-driven transactivation effects should tilt the overall AHR-mediated responses towards anti-inflammatory effects. Exposure of Hepa 1 cells to the partial agonist $\alpha$-naphthoflavone reveals that this compound is effective at repressing cytokinemediated SAA3 induction yet is a relatively poor inducer of DRE-driven transcriptional activity (Figure 3c). This result would support the concept that a highly selective AHR ligand can be identified that would yield anti-inflammatory activity.

Ligand-activated receptors have multiple domains that impart different functionalities, such as DNA binding, ligand binding, dimerization and co-regulator recruitment. However, depending on the manner of activation and the physiological context, the functionalities of soluble receptors can be dissociated from their biological roles, as in the case of $\mathrm{GR}^{28}$ and ER. ${ }^{29}$ Here, we show for the first time that DNA binding is not essential for AHR-mediated repressive effects on NF- $\kappa \mathrm{B}$ transactivation, whereas heterodimerization with ARNT and nuclear translocation are required. Aside from xenobiotic-metabolizing enzyme induction, this is also the first report identifying a functional molecular role of AHR in a biological process, and not just regulation of individual genes. The data presented in this report show the functional interplay between AHR and inflammatory signaling pathways to regulate the expression of multiple APR genes, an important aspect of the hepatic inflammatory response. This report identifies a novel physiological function carried out by the AHR in murine as well as human systems. AHR-mediated transcriptional repression is not conducted in the classical DRE-dependent fashion, but most likely involves multiple protein-protein interaction mechanisms. The fact that dietary exposure to the AHR ligand $\beta$-NF effectively represses cytokine-mediated APR in the liver, as seen in Figure 6 underscores the possibility of utilizing the AHR as a therapeutic target for treatment of inflammatory/autoimmune disease. However, to therapeutically utilize the ability of AHR to function as a repressor of APR, and possibly other inflammatory phenomena, it is necessary to identify selective ligands that would also not induce xenobiotic metabolism.

Supplementary Information accompanies the paper on the Laboratory Investigation website (http://www.laboratoryinvestigation.org)

\section{ACKNOWLEDGEMENTS}

We thank Dr Chris Bradfield for the $A \mathrm{Ar}^{\mathrm{fx} / \mathrm{fx}} \mathrm{Cre}^{\mathrm{Alb}}$ and $\mathrm{Ahr}^{-1-}$ mice. This work was supported by the Public Health Service grant ES04869 from the National Institute of Environmental Health Sciences.

1. Ramadori G, Christ B. Cytokines and the hepatic acute-phase response. Semin Liver Dis 1999;19:141-155.

2. Pascual G, Glass CK. Nuclear receptors versus inflammation: mechanisms of transrepression. Trends Endocrinol Metab 2006;17:321-327.

3. Tian Y, Rabson AB, Gallo MA. Ah receptor and NF-kappaB interactions: mechanisms and physiological implications. Chem Biol Interact 2002;141:97-115.

4. Schmidt JV, Bradfield CA. Ah receptor signaling pathways. Annu Rev Cell Dev Biol 1996;12:55-89.

5. Bacsi SG, Reisz-Porszasz S, Hankinson O. Orientation of the heterodimeric aryl hydrocarbon (dioxin) receptor complex on its asymmetric DNA recognition sequence. Mol Pharmacol 1995;47: 432-438.

6. Barouki R, Coumoul X, Fernandez-Salguero PM. The aryl hydrocarbon receptor, more than a xenobiotic-interacting protein. FEBS Lett 2007;581:3608-3615.

7. Madden CR, Finegold MJ, Slagle BL. Expression of hepatitis B virus $X$ protein does not alter the accumulation of spontaneous mutations in transgenic mice. J Virol 2000;74:5266-5272.

8. Murray IA, Reen RK, Leathery N, et al Evidence that ligand binding is a key determinant of Ah receptor-mediated transcriptional activity. Arch Biochem Biophys 2005;442:59-71.

9. Spencer VA, Sun JM, Li L, et al Chromatin immunoprecipitation: a tool for studying histone acetylation and transcription factor binding. Methods 2003;31:67-75.

10. Levine SL, Petrulis JR, Dubil A, et al A tetratricopeptide repeat half-site in the aryl hydrocarbon receptor is important for DNA binding and trans-activation potential. Mol Pharmacol 2000;58:1517-1524.

11. Petrulis JR, Kusnadi $A$, Ramadoss $P$, et al The hsp90 Co-chaperone XAP2 alters importin beta recognition of the bipartite nuclear localization signal of the Ah receptor and represses transcriptional activity. J Biol Chem 2003;278:2677-2685.

12. Morales JL, Krzeminski J, Amin S, et al Characterization of the antiallergic drugs 3-[2-(2-phenylethyl) benzoimidazole-4-yl]-3hydroxypropanoic acid and ethyl 3-hydroxy-3-[2-(2phenylethyl)benzoimidazol-4-yl]propanoate as full aryl hydrocarbon receptor agonists. Chem Res Toxicol 2008;21:472-482. 
13. Walisser JA, Glover E, Pande K, et al Aryl hydrocarbon receptordependent liver development and hepatotoxicity are mediated by different cell types. Proc Natl Acad Sci U S A 2005;102:17858-17863.

14. Tian Y, Ke S, Denison MS, et al Ah receptor and NF-kappaB interactions, a potential mechanism for dioxin toxicity. J Biol Chem 1999; 274:510-515.

15. Kluve-Beckerman B, Drumm ML, Benson MD. Nonexpression of the human serum amyloid $A$ three (SAA3) gene. DNA Cell Biol 1991;10:651-661.

16. Danesh J, Wheeler JG, Hirschfield GM, et al C-reactive protein and other circulating markers of inflammation in the prediction of coronary heart disease. N Engl J Med 2004;350:1387-1397.

17. Veerhuis R, Boshuizen RS, Familian A. Amyloid associated proteins in Alzheimer's and prion disease. Curr Drug Targets CNS Neurol Disord 2005;4:235-248.

18. Gillmore JD, Lovat LB, Persey MR, et al Amyloid load and clinical outcome in $A A$ amyloidosis in relation to circulating concentration of serum amyloid A protein. Lancet 2001;358:24-29.

19. Malle E, Sodin-Semrl S, Kovacevic A. Serum amyloid A: An acute-phase protein involved in tumour pathogenesis. Cell Mol Life Sci 2009;66:9-26.

20. Cheng N, He R, Tian J, et al Cutting edge: TLR2 is a functional receptor for acute-phase serum amyloid A. J Immunol 2008;181:22-26.

21. Okamoto $H$, Katagiri $Y$, Kiire $A$, et al Serum amyloid $A$ activates nuclear factor-kappaB in rheumatoid synovial fibroblasts through binding to receptor of advanced glycation end-products. J Rheumatol 2008;35:752-756.
22. Lee MS, Yoo SA, Cho CS, et al Serum amyloid A binding to formyl peptide receptor-like 1 induces synovial hyperplasia and angiogenesis. J Immunol 2006;177:5585-5594.

23. Kobayashi $\mathrm{S}$, Okamoto $\mathrm{H}$, Iwamoto $\mathrm{T}$, et al A role for the aryl hydrocarbon receptor and the dioxin TCDD in rheumatoid arthritis. Rheumatology (Oxford) 2008;47:1317-1322.

24. Shimizu H, Yamamoto K. NF-kappa B and C/EBP transcription factor families synergistically function in mouse serum amyloid $A$ gene expression induced by inflammatory cytokines. Gene 1994;149: 305-310.

25. Glass CK, Ogawa S. Combinatorial roles of nuclear receptors in inflammation and immunity. Nat Rev Immunol 2006;6:44-55.

26. Vogel FA, Matsumura F. A new cross-talk between the aryl hydrocarbon receptor and RelB, a member of the NFkappaB family. Biochem. Pharmacol 2008;77:734-745.

27. Hollingshead BD, Beischlag TV, Dinatale BC, et al Inflammatory signaling and aryl hydrocarbon receptor mediate synergistic induction of interleukin 6 in MCF-7 cells. Cancer Res 2008;68: 3609-3617.

28. Reichardt HM, Kaestner $\mathrm{KH}$, Tuckermann J, et al DNA binding of the glucocorticoid receptor is not essential for survival. Cell 1998;93: 531-541.

29. Valentine JE, Kalkhoven E, White R, et al Mutations in the estrogen receptor ligand binding domain discriminate between hormonedependent transactivation and transrepression. J Biol Chem 2000;275:25322-25329. 